COMMUN. SOIL SCI. PLANT ANAL., 33(7\&8), 1305-1322 (2002)

\title{
A NOVEL METHOD FOR MEASUREMENT AND CHARACTERIZATION OF SOIL MACROPOROSITY
}

\author{
Christopher Barton $^{1}$ and Tasos Karathanasis ${ }^{2 * *}$ \\ 'USDA Forest Service, Center for Forested Wetlands \\ Research, Savannah River Ecology Laboratory, Drawer E, \\ Aiken, SC 29802 \\ ${ }^{2}$ Department of Agronomy, University of Kentucky, \\ N-122 Ag. Sci. Bldg, Lexington, KY 40546
}

\begin{abstract}
Quantitative macropore characterizations were performed in large zero-tension soil lysimeters of a Maury silt loam (fine, mixed, mesic Typic Paleudalf) and a Loradale silt loam (fine, silty, mixed, mesic Typic Axgiudoll) soil in an effort to assess potential colloid transport. Steel pipe sections $(50 \mathrm{~cm}$ diameter X $100 \mathrm{~cm}$ length) were hydraulically driven into the soil for lysimeter establishment. A dye tracer was applied into each lysimeter under saturated conditions at eight-hour intervals using $500 \mathrm{~mL}$ pulse applications. After one pore volume elution, the center section of the stained lysimeters was removed, dissected, and photographed. Kubiena tins were inserted into the lysimeter's remaining soil at $15 \mathrm{~cm}$ intervals. Vertically oriented thin sections were prepared from each tin. Pore area, diameter, and orientation were evaluated from thin sections and photographs using commercial grade
\end{abstract}

\footnotetext{
*Corresponding author. E-mail: akaratha@uky.edu
} 
scanners and Photoshop ${ }^{\circledR}$ software. At an input scanning resolution of 60 pixels per $\mathrm{cm}$, the software program was capable of identifying pores with diameters $>160 \mid \mathrm{xm}$. Thin section analysis provided more detail of smaller sized pores $(<1.0 \mathrm{~mm})$, while the cationic nature of the methylene blue dye restricted its presence primarily to the larger macropores. The Loradale soils tended to exhibit increased pore area and pore diameter over that of the Maury in both thin sections and photographs. The Loradale soil also showed a more elaborate and vertically oriented network of pores. Although standard soil physical measurements did not suggest the presence of a restrictive layer in these soils, morphological evidence generated from this methodology suggested otherwise. Colloid leaching experiments performed in separate lysimeters of the same soils in a fashion similar to that used for the dye tracer application showed colloid breakthrough and filtration patterns consistent with the macropore characterization observations obtained through the application of this method.

\section{INTRODUCTION}

The influence of macropores on the transport of contaminants has gained much attention in the last twenty years. Extensive groundwater monitoring and experimental data have revealed that preferential flow through macropores and fractures may be a primary mechanism for rapid leaching of agricultural chemicals and other potential pollutants into surface water and groundwater (1,2). Bouma and Wösten (3) found that the shape of breakthrough curves and saturated and unsaturated hydraulic conductivity are greatly influenced from a few macropores that represent a small percentage of the total volume in undisturbed soil samples. Similar evidence of preferential water and solute flow has been observed under field conditions (4), in undisturbed soil columns (5), and in repacked columns with simulated macropores (6). Moreover, evidence has shown that contaminants, which were generally considered to be immobile in the vadose zone, may be adsorbed by colloidal sized particles and subsequently transported through these preferential flow paths $(7,8)$.

Macropores are generally described as relatively large and somewhat continuous voids through which rapid flow can occur (9). Beven and Germann (10) defined macropores as the pores, which permit non-equilibrium, channeling flow, regardless of their size. Although there is no one classification for macropore size, minimum equivalent macropore diameters from $30 \mid \mathrm{xm}$ to 
3000 ixm have been utilized in various research studies (10). Attempts to quantify and characterize macropores have involved the implementation of one or more physical or morphological methods. Physical methods employ breakthrough curves $(3,5)$, hydraulic conductivity measurements (11), and/or tensiometers (12) as indirect indicators of macroporosity. The morphological approach, on the other hand, evaluates the actual number, size, area distribution and continuity of macropores under natural conditions (13).

Several methods are available for the characterization of macropore morphology. Most of these methods employ the use of thin section analysis $(12,14)$, soil profile photography $(15,16)$, or dye tracers $(13,17)$ to define the macropore area of interest. Then, the size, shape, and configuration of pores are quantified using an image analysis system (14) or manual measurements (12). Although the image analysis system is a preferred method for these types of determinations, the high cost associated with this equipment and degree of expertise needed to operate the unit may not justify its use as a general analytical tool. On the other hand, manual calculation of macropore characteristics is a tedious, labor-intensive endeavor that is prone to a significant amount of subjective error. Computed tomography (CT) scanning (18), and nuclear magnetic resonance (19) have also been implemented for the characterization of macropores and preferential flow paths, but high cost and limited equipment availability have curtailed their widespread use.

In a recent study, Barton and Karathanasis (20) examined the role of soil colloids and their potential to co-transport agrochemicals [atrazine and zinc ( $\mathrm{Zn}$ )] through macropores in a leaching experiment using large zero-tension soil lysimeters. Results from their study showed that colloids moved freely through lysimeters of the Loradale soil, while colloids introduced into lysimeters of the Maury soil were filtered in the matrix. This observation was in contrast to previous leaching experiments in which colloids moved readily through intact soil columns of both soils (21-23). Although the stability of the transported colloids in the Maury soil may have been influenced by electrochemical changes within the lysimeter, which led to flocculation, as the experiment progressed, it is also possible that the particular site chosen for the experiment may not posses the macropore network necessary for colloid mobility. Given this situation, an experiment was initiated to evaluate the extent of the macropore network in the two soils and to assess whether the necessary preferential flow paths for colloid transport were present. The result of these efforts was the development of a simple, low-cost method for performing macropore characterizations using commercial scanners and image editing software (Adobe $\AA$ Photoshop ${ }^{\circledR}$ ). Considering the influence of soil macroporosity on preferential flow and the increasingly recognized contribution of the role of colloids in contaminant transport, the need for a routine method to quantitatively evaluate macropore morphology, such as the one presented in this paper, is evident. 


\section{MATERIALS AND METHODS}

\section{Field Experiment and Soil Samples}

Undisturbed zero-tension lysimeters were prepared in the field at two sites (six per site) of the University of Kentucky Agricultural Experiment Station in Lexington, KY. Soils included in the experiment were a Maury silt loam (fine, mixed, mesic Typic Paleudalf) and a Loradale silt loam (fine, silty, mixed, mesic Typic Argiudoll). A hydraulically driven sampling technique was developed to create the large lysimeters. Steel pipe sections with an inside diameter of $50 \mathrm{~cm}$, wall thickness of $1 \mathrm{~cm}$, and length of 1 meter were used for the cores. The cylinders were beveled at one end to facilitate penetration into the soil. Cylinders were placed vertically on a prepared area in which the vegetation was removed and pushed $=0.51) 1$ into the soil using a 30-ton hydraulic drill rig. A trench was excavated with a backhoe parallel to and at a distance of $0.5 \mathrm{~m}$ from the lysimeter. Soil was removed below the lysimeter with hand tools, thereby creating an "opening" at which the metal cylinder was visible. In this area a 52-cm diameter and a 15-cm long PVC cap was inserted. A male hose fitting was welded into the cap and a polyethylene hose was attached for sample collection. The "opening" was backfilled with soil to hold the cap in place and to support the lysimeter. The lysimeters were subsequently wetted with $5 \mathrm{~L}$ of distilled water to moisten the soil surface.

One pore volume ( «40L) of a $1 \mathrm{gL} \sim "$ methylene blue dye solution was applied to one lysimeter from each soil three times daily (8 hour intervals) in $500 \mathrm{~mL}$ increments, under saturated gravitational flow conditions. Blue water was evident in eluents after two liters of leaching. Two days after the dye application, a core from the center of each lysimeter was dissected using knives and hand shovels. The cores were further carved with hand tools to enhance the stain definition, measured and photographed. The samples were sealed in plastic bags and retained for future reference.

Undisturbed soil samples were obtained with Kubiena tins (15 X $9.5 \mathrm{X}$ $5.5 \mathrm{~cm}$ ) inserted vertically into the soil remaining inside the lysimeter. Tins were oriented so that three samples $(0-15,15-30$, and $30-45 \mathrm{~cm}$ depths $)$ were collected from each lysimeter. The three depths closely represent levels of different horizonation (Ap, BA, and Bti) found in each soil. Soil blocks from the Kubiena tins were air dried and impregnated under vacuum with a polyester resin diluted with acetone (2:1 resin/acetone). To promote hardening of the resin, the samples were irradiated with Co radiation $(870 \mathrm{~Gy} / \mathrm{h}$ for $24 \mathrm{hr})$. Vertically oriented $4 \times 6 \mathrm{~cm}$ thin sections were polished to a 30 (xm thickness and placed on $5 \times 7.5 \mathrm{~cm}$ glass slides. The thin sections were prepared by National Petrographic Services, Inc. (Houston, TX). 
Duplicate soil samples at $15-\mathrm{cm}$ increments were collected adjacent to the lysimeters at each site for physicochemical characterization (Table 1). Particle size analysis was performed using the pipette method (24). Organic carbon (OC) was determined using a Leco Carbon Analyzer, Model CR-12. Saturated hydraulic conductivity was determined by the falling head permeameter method (25), and bulk density was measured using the sarancoated clod (4Ala) method (24). The total porosity was calculated from the equation: total porosity $=100 \mathrm{X}(1-\mathrm{Pb} / \mathrm{Pp})$, where $\mathrm{Pb}=$ bulk density and $\mathrm{Pp}=$ particle density (26). Particle density was determined on a composite sample representing the entire length of the lysimeter from each soil by the pycnometer method (27).

Colloid leaching experiments were conducted in separate lysimeters to test the consistency of the soil macropore characterizations with colloid breakthrough and filtration patterns. The water dispersible colloids were fractionated from the Bt horizons of the Maury and Loradale soils following the methods of Seta and Karathanasis (21). The mean diameter of fractionated colloids was measured using a Quantachrome Corporation microscan particle-size analyzer and expressed on a mass basis. A $300 \mathrm{mg} \mathrm{L}^{1}$ colloid suspension from each soil was applied onto duplicate Maury and Loradale lysimeters, respectively, under unsaturated, gravitational flow conditions. The colloid mixture was applied in the field three times daily ( 8 hour intervals) in $500 \mathrm{~mL}$ increments. Eluents from the lysimeters were monitored with respect to volume, and colloid concentration. Colloid concentrations in the eluents were determined using a Bio-Tek multichannel (optical densitometer with fiber-optic technology; Bio-Tek Instruments, Winooski, VT) microplate reader precalibrated with known concentrations of each colloid at $540 \mathrm{~nm}$.

\section{Macropore Characterization Using Photoshop}

For the following discussion, refer to the Adobe ${ }^{\circledR}$ Photoshop $®$, Version 5.0, User's Guide (28) for an illustration of menus and toolbars used in this experiment. In an effort to make comparisons between samples more accurate, each thin section was examined to determine a common maximum available surface area for determination. In this experiment, a $3 \times 5 \mathrm{~cm}$ area was available on each slide. The thin sections were placed, glass side down, on a Hewlett Packard Scan Jet 5100c flatbed scanner and scanned in black and white at 60 pixels per $\mathrm{cm}^{2}$. At this resolution, identification of pores with diameters $>160 \mathrm{xm}$ is possible. The scanned images were saved as bitmap (BMP) files and reopened in Adobe ${ }^{\circledR}$. Photoshop® 5.0.

In Photoshop ${ }^{\circledR}$, the images were cut to 3 X $5 \mathrm{~cm}$ using the "crop" tool. The image was enlarged to $9 \times 15 \mathrm{~cm}$ by choosing the "Image" menu, then 
Table 1. Physicochemical Properties of the Soils Included in the Study

\begin{tabular}{|c|c|c|c|c|c|c|c|c|}
\hline Depth $(\mathrm{cm})$ & $\begin{array}{c}\text { Sand } \\
(2-0.5 \mathrm{~mm}) \\
(\%)\end{array}$ & $\begin{array}{c}\text { Silt } \\
(50-2 / \mathrm{Am}) \\
(\%)\end{array}$ & $\begin{array}{l}\text { Clay } \\
(<2 / \mathrm{xm}) \\
(\%)\end{array}$ & $\begin{array}{l}\text { Porosity" } \\
(\%)\end{array}$ & $\begin{array}{c}\text { Organic } \\
\text { Matter } \\
(\%)\end{array}$ & $\begin{array}{c}\text { Hydraulic } \\
\text { Conductivity } \\
\left(\mathrm{cmmin}^{11}\right)\end{array}$ & $\begin{array}{c}\text { Bulk } \\
\text { Density } \\
\left(\operatorname{gcnf}^{3}\right)\end{array}$ & $\mathrm{pH}(1: 1)$ \\
\hline \multicolumn{9}{|c|}{ Maury Silt Loam } \\
\hline $0-15$ & 4.6 & 77.3 & 18.1 & 44.1 & 2.93 & $2.4 \pm 1.4$ & $1.47 \pm 0.21$ & 5.5 \\
\hline $15-30$ & 5.0 & 65.4 & 29.6 & 44.8 & 1.89 & $2.2 \pm 2.1$ & $1.45 \pm 0.05$ & 5.8 \\
\hline $30-45$ & 5.2 & 61.6 & 33.2 & 47.1 & 0.86 & $1.9 \pm 0.4$ & $1.39 \pm 0.39$ & 5.7 \\
\hline \multicolumn{9}{|c|}{ Loradale Silt Loam } \\
\hline $0-15$ & 5.1 & 78.5 & 16.4 & 51.2 & 5.86 & $3.1 \pm 1.7$ & $1.24 \pm 0.21$ & 5.5 \\
\hline $15-30$ & 12.6 & 68.3 & 19.1 & 47.2 & 3.85 & $2.6 \pm 1.2$ & $1.34 \pm 0.09$ & 5.4 \\
\hline $30-45$ & 14.3 & 57.8 & 27.9 & 47.6 & 3.45 & $0.7 \pm 0.4$ & $1.33 \pm 0.12$ & 6.0 \\
\hline
\end{tabular}

Standard deviations of the mean were less than $5 \%$, unless otherwise indicated on the table.

${ }^{\text {il }}$ Mean particle densities of 2.63 and $2.54 \mathrm{~g} \mathrm{~cm}^{-3}$ were used to calculate porosity for the Maury and Loradale soils, respectively. 
"Size" and inputting the desired size at the prompt. Enlarging the picture tended to pixelate the image, which further enhanced the segregation between pore and non-pore areas. The "zoom" tool was chosen to enlarge a representative pore (white area), then the pore was selected using the "wand" tool. Once selected, areas containing similar shades were chosen by clicking "Select" on the menu then "Similar." At this point it was necessary to determine whether or not the selected area was representative of the actual pore space. In the Window menu under "Paletts" and "Options," the tolerance of area selected as "similar" was adjusted. Once satisfied with an adequate tolerance level, the selected area was filled with the foreground color (i.e., black) by selecting "Edit" on the menu and choosing "Fill." If necessary, individual pixels from suspected pore areas, which were not selected in earlier steps can be incorporated into the pore using the "Pencil" tool.

To determine the percent area of pore space, the option "Image" and then "Histogram" was used from the menu. The number of pixels shown in the "Histogram" was recorded in the dialog box for the entire image. Next, clicking on "Select" and "Color Range" from the menu allows to re-select the "Sampled Colors" (pores); finally, going back to the "Histogram" dialog box allows recording the number of pixels for the colored area. The \% pore area was expressed as colored pixels/total pixels X 100. The area of individual pores in a thin section was also calculated by selecting a specific pore with the "direct selector" tool or the "lasso" tool, then determining the number of selected pixels in the "Histogram" dialog box. Based upon the input-scanning rate, the size of each pixel is known, thus conversion to $\mathrm{mm}^{2}$ is possible. In addition, the determination of length and/or width of whole pores or portions of pores exhibiting abrupt size changes were performed from the "View" menu, selecting "Show Ruler" and using the "line" tool as a ruler. With this information, average weighted pore diameters were calculated for each sample.

Slide photographs of the stained soils were scanned with a Nikon® LS2000 Electronic Imaging Slide Scanner. Images were scanned in color at 60 pixels per $\mathrm{cm}$ and saved as bitmap files. Characterization of the stains was performed using Photoshop ${ }^{\circledR}$ in a fashion similar to that of the thin sections. However, cropping of the initial images to a uniform size was not possible because the size of the peds and orientation of the picture was different for each sample. Thus, final results pertaining to area and diameter had to be calculated based on the original measurements made in the field and verified with the retained samples. The only other major difference between the thin section and photograph characterization involved selection of the pore area. Since the photographs did not exhibit the void space, which is characteristic of pores in thin sections, blue stained areas were selected to represent the pore area. Once selected, the method proceeded as described above. 


\section{RESULTS AND DISCUSSION}

\section{Evaluation of Method}

Macropore characteristics were determined through the use of commercial grade image scanners and Photoshop ${ }^{\circledR}$ software (Table 2). The procedure provided a minimum detectable pore diameter of 160 (jun, which is well within the accepted range for macropore identification (10). Although the thin sections could be analyzed in color, it was discovered that the black and white option produced a more distinct contrast between the pore and non-pore space and even provided a good quantification measure of concretions within the soil matrix. However, the blue dye stain was not clearly distinguishable from the soil matrix in a black and white image, particularly in the dark color surface horizon (mollic epipedon) of the Loradale soil. Thus, scanning of the dyed images in color was necessary.

Analysis of the thin sections revealed that the Loradale soil exhibited greater macroporosity than the Maury soil (Table 2). This is in agreement with the total porosity differences observed in soil sample characterizations (Table 1). The Loradale also exhibited an increased pore size diameter in the upper $30 \mathrm{~cm}$, while in the $30-45 \mathrm{~cm}$ depths both soils had similar pore size distributions. A corresponding trend was observed with the hydraulic conductivity. Apparently, high organic matter and low clay content in the upper $30 \mathrm{~cm}$ of the Loradale soil promoted macropore formation, while increased clay concentration and associated structural changes within the 30 to $45 \mathrm{~cm}$ may have limited their expression. Bulk density data from the two soils are also reflective of the observed macroporosity trends (Table 1). Thin sections of the Loradale soil, which exhibited a lower bulk density, revealed the presence of several large pores that are similar in size to worm channels (Fig. 1). A positive correlation between earthworm abundance and macroporosity has been reported by Shipitalo and Protz (29), while an inverse relationship between earthworm abundance and bulk density has been noted by Binet et al. (30). In a study by Clements et al. (31), bulk density was found to increase from 1.0 to $1.6 \mathrm{gem}^{\prime \prime \prime 3}$ in a grassland soil, which was kept free of earthworms by repeated pesticide application for 20 years.

Pore orientation differed greatly between the two soils as indicated by thin section analysis. The Maury soil exhibited a sparse, randomly oriented pattern of linear and round voids in the upper $30 \mathrm{~cm}$, while the $30-45 \mathrm{~cm}$ depths were dominated by several interconnecting planar voids and channels (Fig. 2). Pore area measurements reflected this trend. The macroporosity decreased from $23.9 \%$ at the surface to $3.1 \%$ at the $15-30 \mathrm{~cm}$ depth, then increased to $13.0 \%$ at the 30 $45 \mathrm{~cm}$ depth. In contrast, the Loradale thin sections exhibited a distinct network of interconnected horizontal and vertical planar voids and channels throughout the $45 \mathrm{~cm}$ depth (Fig. 1). 
Táble 2. Calculated Surface Area and Mean Diameter of Pores and Stains from Scanning Image Analysis

\begin{tabular}{|c|c|c|c|c|c|c|c|c|}
\hline \multirow[b]{2}{*}{$\begin{array}{l}\text { Depth } \\
(\mathrm{cm})\end{array}$} & \multicolumn{4}{|c|}{ Maury Silt Loam } & \multicolumn{4}{|c|}{ Loradale Silt Loam } \\
\hline & $\begin{array}{c}\text { Pore } \\
\text { Area } \\
\left(\mathrm{mm}^{2} / 100 \mathrm{~mm}^{2}\right)\end{array}$ & $\begin{array}{c}\text { Pore } \\
\text { Diameter }^{2} \\
(\mathrm{~mm})\end{array}$ & $\begin{array}{c}\text { Stain } \\
\text { Area } \\
\left(\mathrm{mm}^{2} / 100 \mathrm{~mm}^{2}\right)\end{array}$ & $\begin{array}{c}\text { Stain } \\
\text { Diameter } \\
(\mathrm{mm})\end{array}$ & $\begin{array}{c}\text { Pore } \\
\text { Area } \\
\left(\mathrm{mm}^{2} / 100 \mathrm{~mm}^{2}\right)\end{array}$ & $\begin{array}{c}\text { Pore } \\
\text { Diameter } \\
(\mathrm{mm})\end{array}$ & $\begin{array}{c}\text { Stain } \\
\text { Area } \\
\left(\mathrm{mm}^{2} / 100 \mathrm{~mm}^{2}\right)\end{array}$ & $\begin{array}{c}\text { Stain } \\
\text { Diameter } \\
(\mathrm{mm})\end{array}$ \\
\hline $0-15$ & 23.9 & 2.18 & 30.9 & 1.41 & 30.1 & 2.02 & 27.5 & 2.66 \\
\hline $15-30$ & 3.1 & 0.78 & 16.6 & 2.29 & 25.7 & 1.70 & 26.2 & 3.10 \\
\hline $30-45$ & 13.0 & 1.31 & 20.9 & 1.67 & 16.9 & 1.46 & 24.6 & 2.48 \\
\hline
\end{tabular}

Pore area and diameters were evaluated from thin sections.

${ }^{\mathrm{a}}$ A weighted average was employed to determine mean pore diameter. 
(a)

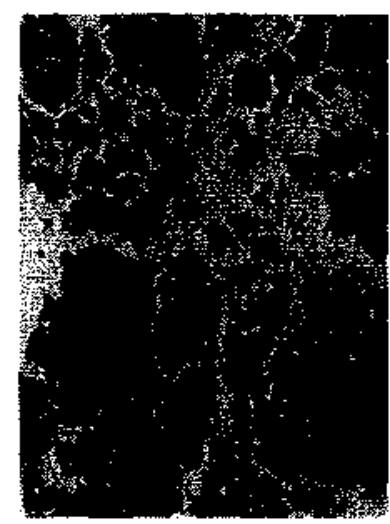

(b)

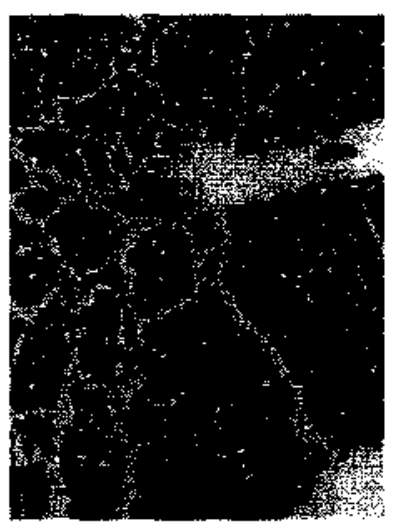

(c)

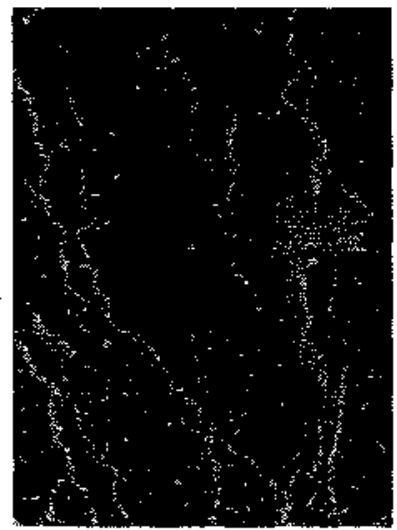

$9 \mathrm{~mm}$
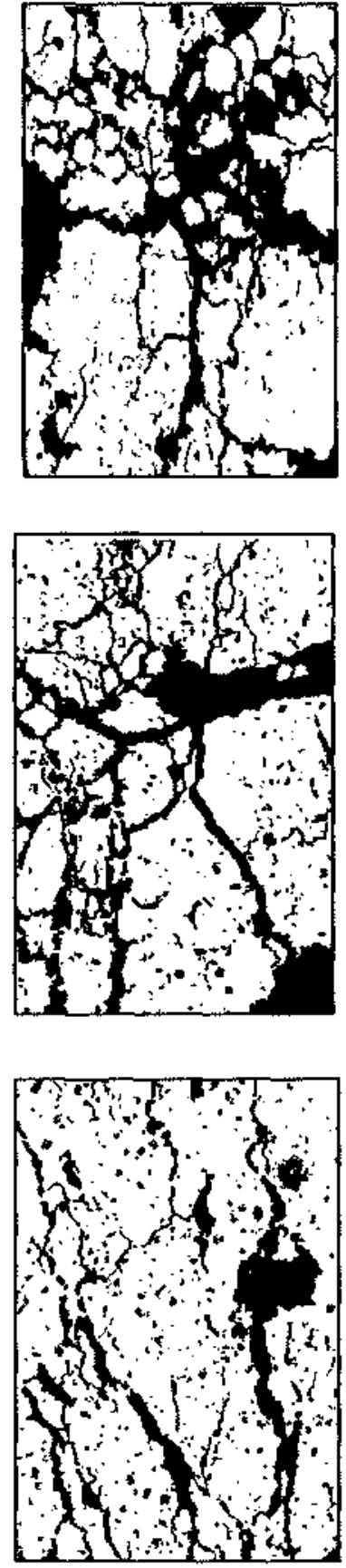
Scanned photographs of the methylene blue dye tracer tended to exhibit an increased pore area and pore diameter over that of the thin sections in both soils (Table 2). This may be attributed to the cationic nature of the dye, which causes it to be strongly adsorbed to the walls of transmitting pores and excluded from the mobile solution before entry into small pores takes place (16). Dunn and Phillips (32) reported that only a few large-diameter pores $(>1.0 \mathrm{~mm})$, which account for only a portion of the total porosity, may be responsible for $>70 \%$ of the water flux in forest soils and in agricultural plots. Thus, the staining method is more prone to express the preferential flow paths, which are dominated by the larger size pores, while the thin sections provide a better view of total porosity. Visual comparison of the images clearly reveals these differences, where thin sections contain many small pores with diameters $<1.0 \mathrm{~mm}$ (Figs. 1 and 2), while the dye photographs are dominated by a few pores with diameters $>1.0 \mathrm{~mm}$ (Fig. 3). Visual examination of the pictures also indicates that the stains primarily represent biopores such as root channels and worm paths, while the thin sections contain both nonbiological and biologically-induced pores. Given that the dye was applied under unsaturated, gravitational flow conditions, flow paths are going to be oriented toward the direction of the least resistance; i.e., the largest and most continuous voids.

\section{Colloid Transport Experiment}

Data from the colloid leaching experiments were transformed into BTCs based on reduced concentration (ratio of effluent concentration to influent concentration $=\mathrm{C} / \mathrm{Co}$ ) versus pore volume of suspension passed through the lysimeters. Both Loradale lysimeters showed an initial rapid breakthrough to $\mathrm{C} / \mathrm{Co}$ values near 1.0 by the first 0.4 pore volumes (Fig. 4). The BTCs subsequently declined after 0.4 and 0.6 pore volumes of leaching in the Loradale 1 and 2 lysimeters, respectively. Although a decline was evident, colloid breakthrough remained at or above 0.5 for the remainder of the experiment. Colloid transport through the Maury lysimeters, on the other hand, was essentially absent. The Maury 1 lysimeter displayed basically no breakthrough ( $\mathrm{C} / \mathrm{Co}<0.05)$ of colloid through one pore volume of leaching, while the Maury 2 lysimeter exhibited a slight and brief breakthrough $(\mathrm{C} / \mathrm{Co}=0.2)$ during this period (Fig. 4).

Figure 1. Macropore attributes of thin sections from (a) 0-15 cm; (b) $15-30 \mathrm{~cm}$; and(c) $30-45 \mathrm{~cm}$ depths in the Loradale lysimeter. The left column represents the scanned thin section, while the right column represents images of the pore space (gray) and concretions (black) from the Photoshop ${ }^{\circledR}$ program. 
(a)

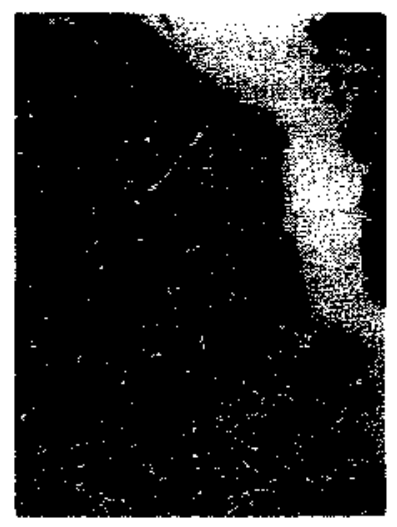

(b)

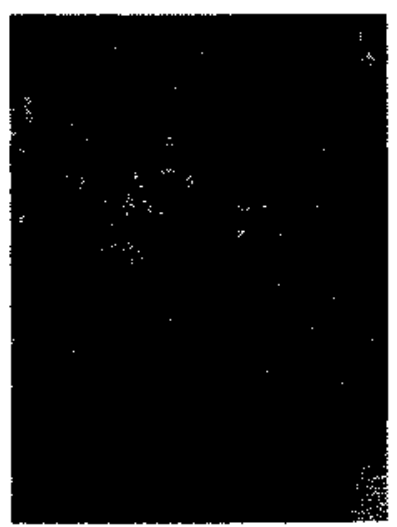

(c)

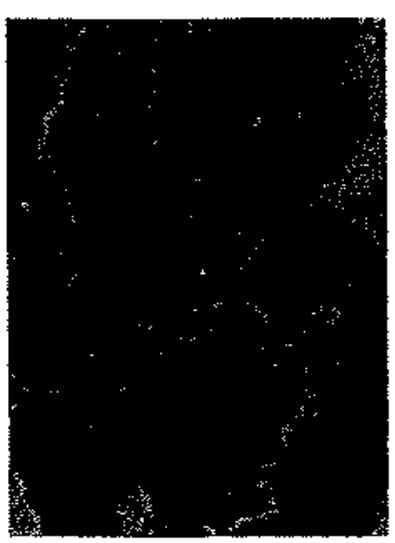

$9 \mathrm{~mm}$
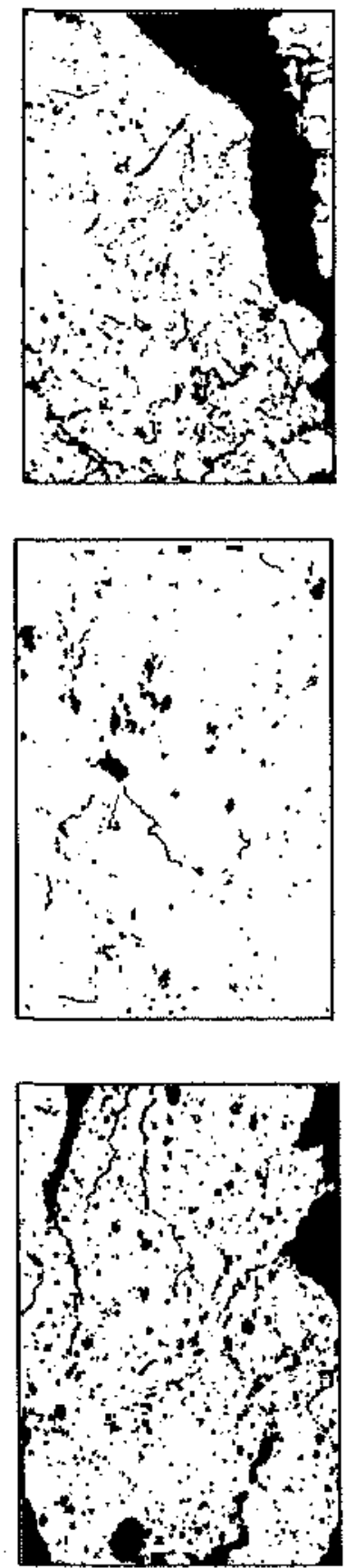
There are several factors that could contribute to the colloid breakthrough differences observed between the two soils. Physical analyses, as discussed earlier, revealed that the Maury soil exhibited a higher bulk density, lower hydraulic conductivity and lower porosity than the Loradale soil, which may have provided a less condúcive environment for colloid mobility (Table 1). In addition, the mean diameter of the Maury colloid was much greater $(700 \mathrm{~nm}$ vs. $300 \mathrm{~nm}$ ) than that of the Loradale, which would make it more susceptible to filtration within the pores of the lysimeter. Certain physicochemical characteristics of the Maury soil and colloid may have also contributed to the differences in colloid breakthrough. According to Barton and Karathanasis (20), lower electrophoretic mobility, organic carbon content and cation exchange capacity, and higher $\mathrm{Fe}$ and $\mathrm{Al}$ concentrations of the Maury colloid over that of the Loradale colloid make it more susceptible to flocculation under the conditions of the leaching experiment.

However, previous work has shown that Maury and Loradale water dispersible colloids by themselves (21), in the presence of atrazine (22), and in the presence of $\mathrm{Zn}$ (23) were readily transported through intact columns from both the Maury and Loradale soil series, respectively. Therefore, the contrasting colloid transport and/or retention patterns in the lysimeters of the two soils cannot be adequately explained by electrochemical factors alone. Moreover, physical measurements and macro-morphological observations did not suggest the presence of a highly compacted zone or discontinuity within the Maury soil that would restrict or inhibit colloid movement. However, the dye application experiment revealed that the Loradale lysimeter contained many vertically oriented flow paths. Staining was evident in vaughs, fissures and channels throughout the length of the lysimeter. The Maury lysimeter also exhibited similar vertically oriented flow paths to a depth of $15 \mathrm{~cm}$. Between the depths of 15 and $20 \mathrm{~cm}$ from the surface, however, the dye moved laterally across a planar fissure that was parallel to the soil's surface. Dissection of peds from this zone showed a complete staining of the planar area. Below this zone vertical movement of the dye was reinitiated, but the stained path was limited to a few channels.

The loss of vertically oriented pores in the 15 to $20 \mathrm{~cm}$ depth may be the result of mechanical compaction and the formation of a plow-pan from past agricultural activities. Interpretations derived from the thin section analysis support this explanation and more detailed field observations confirmed its

Figure 2. Macropore attributes of thin sections from (a) $0-15 \mathrm{~cm}$; (b) $15-30 \mathrm{~cm}$; and(c) $30-45 \mathrm{~cm}$ depths in the Maury lysimeter. The left column represents the scanned thin section, while the right column represents images of the pore space (gray) and concretions (black) from the Photoshop ${ }^{\circledR}$ program. 


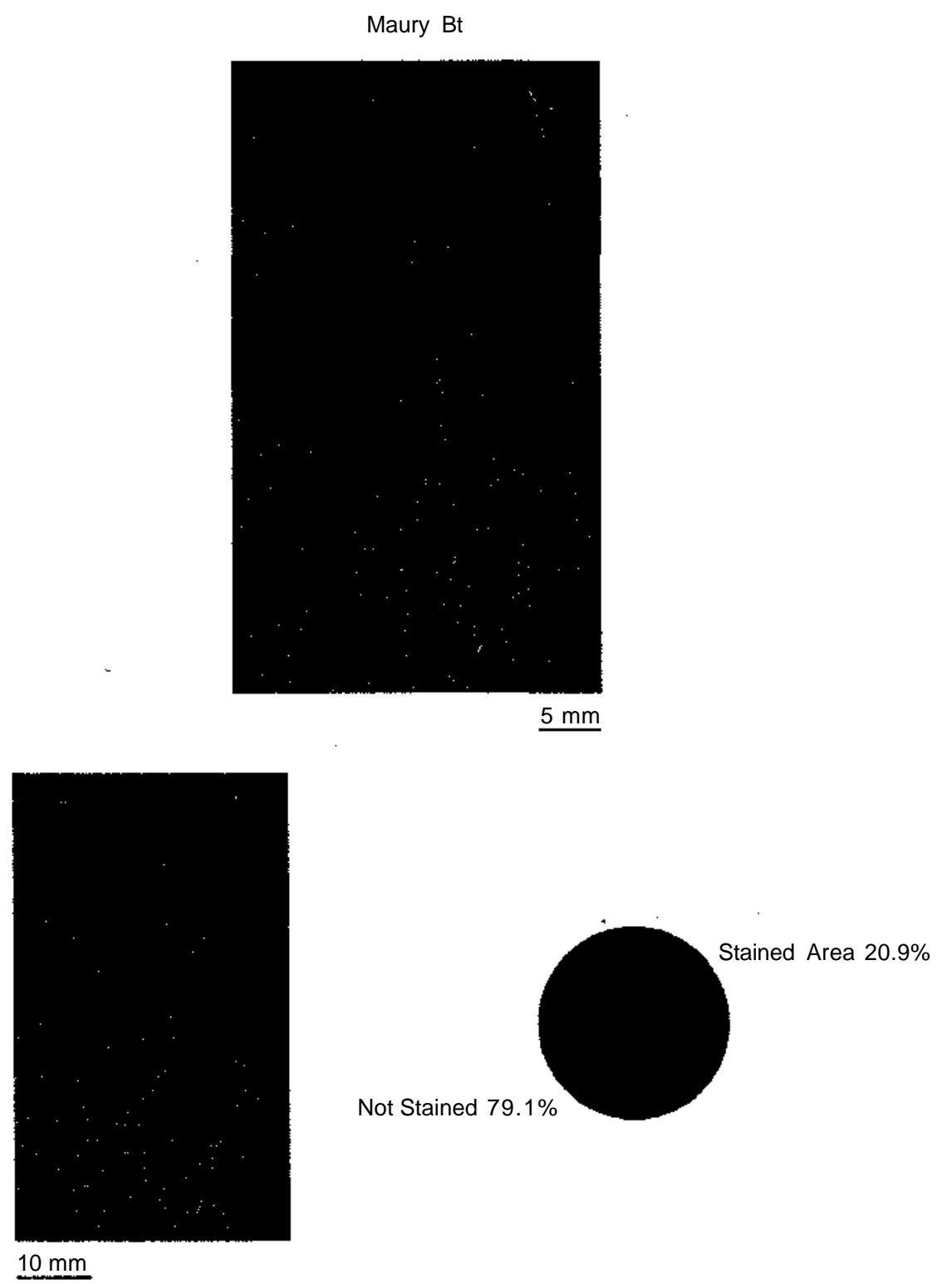

Figure 3. Example of the methylene blue stain from the Bt horizon of a Maury lysimeter. 


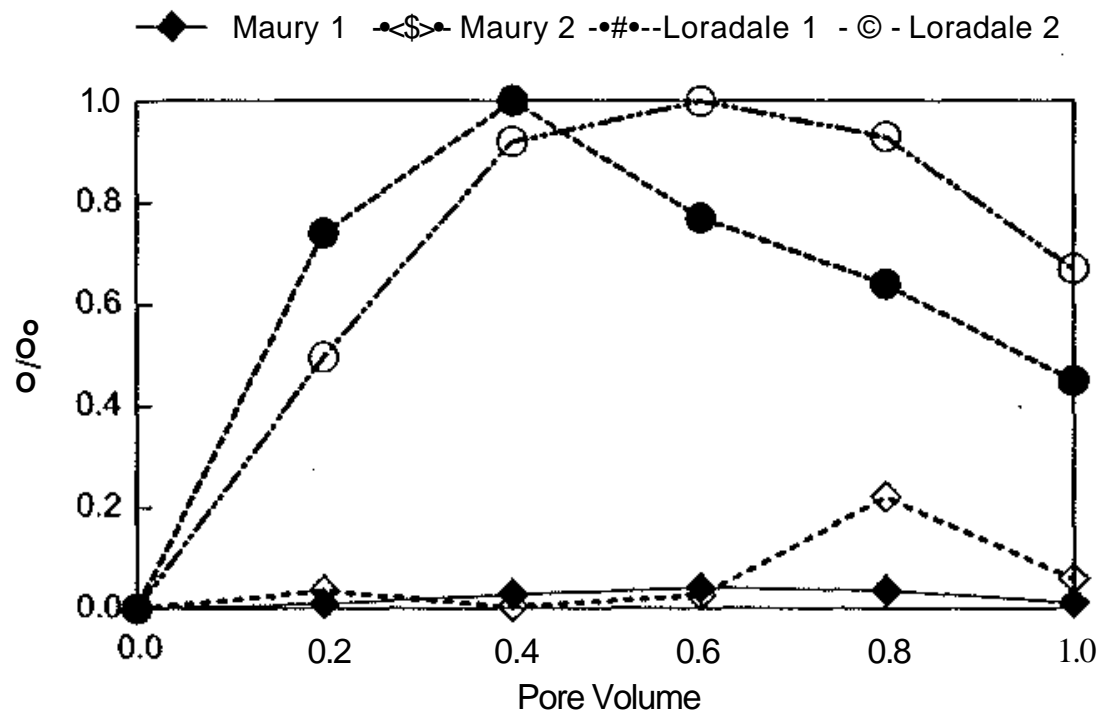

Figure 4. Colloid breakthrough in the Maury and Loradale lysimeters.

presence. Similar disruptions in the continuity of pore channels and inter-pedal packing were described in a compacted Carrot River soil layer at $15 \mathrm{~cm}$ using CT scanning by Grevers et al. (18). In addition, Quisenberry and Phillips $(33,34)$ observed channel formation, similar to that observed with the dye tracer, below the tilled-untilled interface in a Maury soil of an adjacent site. Due to its unrestricted flow path, adequate pore area and sufficient pore diameter, colloids were successfully transported through the Loradale lysimeters. On the other hand, colloid transport was inhibited in the Maury lysimeters by a lack of interconnectivity between pores due to a thin discontinuity at $15 \mathrm{~cm}$, and a decreased average pore diameter below the surface horizon (Table 2).

\section{CONCLUSIONS}

Commercial grade scanners and image editing software were utilized to obtain a morphological characterization of macropores in Maury and Loradale silt loam soils. The Photoshop ${ }^{\circledR}$ software program enabled the quantification of pore area, diameter, and continuity from both thin sections and photographs of dye tracers. The thin sections showed a more elaborate and detailed view of pores > $160 \mathrm{Vim}$ in effective diameter. Characterizations derived from the staining technique tended to emphasize the larger 
size pores, particularly biopores, due to the cationic nature of the methylene blue dye and experimental boundary conditions associated with the leaching procedure. However, the dye tracer provided evidence pertaining to the direction of flow and orientation of pores within the lysimeter that could not be deduced from thin section analysis. The Loradale soil was found to exhibit increased macropore area and effective pore diameter over that of the Maury. Thin section and tracer results revealed that the Loradale contained a well-developed network of vertically oriented pores throughout the $45 \mathrm{~cm}$ depth. The Maury soil, on the other hand, exhibited a disruption in pore continuity at the $15 \mathrm{~cm}$ depth. Physical and morphological evidence corroborated the presence of a compacted layer, which may be responsible for the discontinuity. Based upon this evidence, the pore network observed in the Loradale soil is more conducive for colloid transport. Preferential flow and transport of colloid-sized material through the Maury soil, however, is hindered by a poorly developed and weakly interconnected macropore system. The methodology presented in this paper stands to serve as a simple analytical tool for performing macropore characterizations, without the cost, time or accessibility constraints associated with the hightech image analysis procedures.

\section{REFERENCES}

1. Li, Y.; Ghondrati, M. Preferential Transport of Nitrate Through Soil Columns Containing Root Channels. Soil Sci. Soc. Am. J. 1994,58, 653-659.

2. Thomas, G.W.; Phillips, R.E. Consequences of Water Movement in Macropores. J. Environ. Qual. 1979, 8, 149-152.

3. Bouma, J.; Wösten, J.M. Flow Patterns During Extended Saturated Flow in Two Undisturbed Swelling Clay Soils with Different Macrostructures. Soil Sci. Soc. Am. J. 1979, 43, 16-21.

4. Everts, C.J.; Kanwar, R.S.; Alexander, E.C.; Alexander, S.C. Comparison of Tracer Mobilities Under Laboratory and Field Conditions. J. Environ. Qual. 1989,8,491-498.

5. Singh, P.; Kanwar, R. Preferential Solute Transport Through Macropores in Large Undisturbed Saturated Soil Columns. J. Environ. Qual. 1991, 20, 295-300.

6. Czapar, G.F.; Horton, R.; Fawcett, R.S. Herbicide and Tracer Movement in Soil Columns Containing an Artificial Macropore. J. Environ. Qual. 1992, 21, 110-115.

7. Ouyang, Y.; Shinde, D.; Mansell, R.S.; Harris, W. Colloid-Enhanced Transport in Subsurface Environments: A Review. Crit. Rev. Environ. Sci. Technol. 1996, 26, 189-204. 
8. McCarthy, J.F.; Zachara, J.M. Subsurface Transport of Contaminants. Environ. Sci. Technol. 1989, 23, 496-503.

9. Nielsen, D.R.; van Genuchten, M.T.; Biggar, J.W. Water Flow and Solute Transport Processes in the Unsaturated Zone. Water Resour. Res. 1986, 2, 89-108.

10. Beven, K.; Germann, P. Macropores and Water Flow in Soils. Water Resour. Res. 1982,18, 1311-1325.

11. Bouma, J.A.; Jongerius, A.; Boersma, O.; Jager, A.; Schoonderbeck, D. The Function of Different Types of Macropores During Saturated Flow Through Four Swelling Soil Horizons. Soil Sci. Soc. Am. J. 1977, 41, 945-950.

12. Bouma, J.; Belmans, C.F.M.; Dekker, L.W. Water Infiltration and Redistribution in a Silt Loam Subsoil with Verticle Worm Channels. Soil Sci. Soc. Am. J. 1982, 46, 917-921.

13. Singh, P.; Kanwar, R.S.; Thompson, M.L. Measurement and Characterization of Macropores by Using AUTOCAD and Automatic Image Analysis. J. Environ. Qual. 1991;20, 289-294.

14. Ringrose-Voase, A.J.; Bullock, P. The Automatic Recognition and Measurement of Soil Pore Types by Image Analysis and Computer Prdgrams. J. Soil Sci. 1984, 35, 673-684.

15. Gächter, R.; Ngatiah, J.M.; Stamm, C. Transport of Phosphate from Soil to Surface Waters by Preferential Flow. Environ. Sci. Technol. 1998, 32, 1865-1869.

16. Smettem, K.R.J.; Collis-George, N. Statistical Characterization of Soil Biopores by Using a Soil Peel Method. Geoderma 1985, 36, 27-36.

17. Amoozegar, K.L.A.; Robarge, W.P.; Buol, S.W. Water Movement and Solute Transport Through Saprolite. Soil Sci. Soc. Am. J. 1997, 61, 1738-1745.

18. Grevers, M.C.J.; Jong, E.D.; Arnaud, R.J.S. The Characterization of Soil Macroporosity with CT Scanning. Can. J. Soil Sci. 1989, 69, 629-637.

19. MacFall, J.S.; Johnson, G.A. Use of Magnetic Resonance Imaging in the Study of Plants and Soils. SSSA Spec. Publ. 1994, 36, 99-113.

20. Barton, CD.; Karathanasis, A.D. Colloid-Enhanced Transport of Atrazine and Zinc Through Soil Monoliths. Water Air Soil Pollut. 2002, In press.

21. Seta, A.K.; Karathanasis, A.D. Stability and Transportability of Water Dispersible Soil Colloids. Soil Sci. Soc. Am. J. 1997, 61, 604-611.

22. Seta, A.K.; Karathanasis, A.D. Atrazine Adsorption by Soil Colloids and Co-transport Through Subsurface Environments. Soil Sci. Soc. Am. J. 1997, 61, 612-617.

23. Karathanasis, A.D. Subsurface Migration of Copper and Zinc Mediated by Soil Colloids. Soil Sci. Soc. Am. J. 1999, 63, 830-838. 
24. Natural Resources Conservation Service, Soil Survey Laboratory Methods Manual; Rep. No. 42 Soil Survey Investigations, USDA: Washington, DC, 1996.

25. Klute, A.; Dirksen, C. Hydraulic Conductivity and Diffusivity: Laboratory Methods. In Methods of Soil Analysis. Part 1. Physical and Mineralogical Methods; Klute, A., Ed.; Agron. No. 9, ASA-SSSA: Madison, WI, 1986; 687-735.

26. Hanks, R.J. Applied Soil Physics, Soil Water and Temperature Applications, 2nd Ed.; Springer-Verlag: New York, 1992.

27. Blake, G.R.; Hartage, K.H. Bulk Density. In Methods of Soil Analysis. Part 1. Physical and Mineralogical Methods, 2nd Ed.; Klute, A., Ed.; Agron. No. 9, ASA-SSSA: Madison, WI, 1986; 363-382.

28. Adobe ${ }^{\circledR}$ Photoshop ${ }^{\circledR}$. User Guide for Macintosh and Windows, Adobe Systems Incorporated: San Jose, CA, 1998; Version 5.0.

29. Shipitalo, M.J.; Protz, R. Comparison of Morphology and Porosity of a Soil Under Conventional and Zero Tillage. Can. J. Soil Sci. 1987,67,445-456.

30. Binet, F.; Hallaire, V.; Curmi, P. Agricultural Practices and the Spatial Distribution of Earthworms in Maize Fields. Relationships Between Earthworm Abundance, Maize Plants and Soil Compaction. Soil Biol. Biochem. 1997, 29, 577-583.

31. Clements, R.O.; Murry, P.J.; Sturdy, R.G. The Impact of 20 Years' Absence of Earthworms and Three Levels of N Fertilizer on a Grassland Soil Environment. Agric. Ecosyst. Environ. 1991, 36, 75-85.

32. Dunn, G.H.; Phillips, R.E. Macroporosity of a Well-Drained Soil Under No-Till and Conventional Tillage. Soil Sci. Soc. Am. J. 1991,55, 817-823.

33. Quisenberry, V.L.; Phillips, R.E. Percolation of Simulated Rainfall Under Field Conditions. Soil Sci. Soc. Am. J. 1976, 40, 484-489.

34. Quisenberry, V.L.; Phillips, R.E. Displacement of Soil Water by Simulated Rainfall. Soil Sci. Soc. Am. J. 1978, 42, 675-679. 